\title{
Holo Study - Mixed Reality Framework for Industrial Engineering Education and Training
}

\author{
Meysam Minoufekr* and Peter Plapper \\ Department of Engineering, University of Luxembourg, Luxembourg
}

Submission: December 2, 2020; Published: December 18, 2020

*Corresponding author: Meysam Minoufekr, Department of Engineering, University of Luxembourg, Luxembourg

\section{Abstract}

Nowadays, students struggle with understanding complex production processes and kinematics of machine tools and robots. While professors mostly have been dealing with these subjects for many years, students have only short time to be introduced to the complex nature of these topics. Mixed Reality allows students to engage hands-on in their subjects to reach new dimensions of understanding. Making challenging topics for students accessible by creating a more visual and tactile experience. The applications for entertainment and gaming are off the charts, but the implications for augmented reality in education and science are also undoubtedly massive. The project focusses on making education as interactive as possible, which helps both, teachers and students receive a unique tool for communicating phenomena and processes that are difficult to describe verbally. As a result, a complex knowledge becomes simple, an involvement of students grows, the quality of education increases.

Keywords: Augmented Reality; Mixed Reality; Digital Training Methods; Smart Engineering

\section{Introduction}

There are many ways for students and trainees to be educated and trained about skills and knowledge they need, e.g., classroom lectures with textbooks, computers, handheld devices, and other electronic appliances. The choice of learning innovation depends not only on an individual's access to the provided technologies and the infrastructure, but also on the subject the student has to study and the environmental setup. In a rapidly changing society where there is a great deal of available information and knowledge, adopting and applying information at the right time and right place is needed to main efficiency in both school and business settings. Mixed Reality (MR) is one technology that dramatically shifts the location and timing of education and training. This paper describes, how Mixed Reality (MR) and Virtual Reality were successfully implemented in the master program 'Master of Sustainable Product Creation' at the University of Luxembourg and how those approaches were applied to education and training, potentially impacting other engineering courses in the future.

\section{Goal of the Project}

The reasoning behind the project "HoloStudy" and its main innovation is to give both, students and teachers an innovative way to illustrate the complex matter of the lecture "Factory Design" taught in the first semester of the Master of Science in Engineering - Sustainable Product Creation (Figure 1).

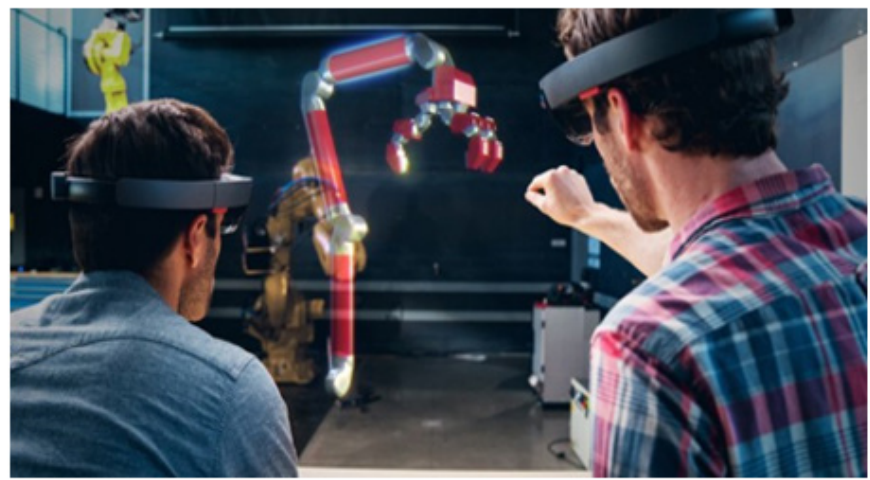

Figure 1: Latest HoloLens demo dazzles with holographic robot spiders and machine tools [2]. 
Classes supported by the project allow to view the objects and phenomena using 3D holograms in the space around the student and not anymore on a flat 2D image on a book or presentation chart where the spatial complexity of a machine design would get lost. This helps students to graphically interpret and explain manufacturing technologies and manufacturing processes. In addition, the project enables students to analyze and to identify logical and structural components of complex manufacturing systems. Integrating Microsoft's HoloLens in the courses "Digital Factory Planning" and "Production technologies and industrial management" finally empowers students to apply their acquired knowledge and gained skills to directly plan and study production processes in a virtual/mixed reality environment.

Due to the unique capability of Virtual and Mixed Reality technologies, the teacher and the students can see and interact with the same hologram, which creates great opportunities for collaborative teaching. Based on these functionalities, students can evaluate alternatives concerning different types of production.

One key aspect of the pedagogical reasoning behind the project and its main innovation, is the fact that the proposed solutions turns group lessons into more encouraging teamwork. With the help of special gestures and voice commands, students and teachers simultaneously interact with the three-dimensional representation and can interact actively. The holograms provided by VR/MR devices enable production and mechanical engineering students to learn things, they would not be able to learn from studying lecture notes or real machines. Industrial robots and machine tools are visible and interact in isolation from other parts of the production system, helping students to design new solutions and assess existing case studies of industrial process planning. Importantly, if something goes wrong in a production simulation, students will not get hurt. The dangerous situation, which is always present in a physical production environment, is eliminated by means of decoupling in the virtual training environment.

\section{Project Realization and Methodology}

The MR lessons are taught using a virtual class environment (Figure 2), in which laboratory work and holographic content help to underline the lessons outcome. The challenge is the design of the spatial representation of the cases studies. The focus on production systems and robotics provides a starting point, because 3D models of machine tools and robots are produced by directly integrating students to contribute to project design and implementation. Skills in CAD design and construction, which the students already acquired during their studies, help to design the course content based on holograms. This way, students are actively part of the teaching program, which enables them the chance to demonstrate their gained skills on a hands-on use case.

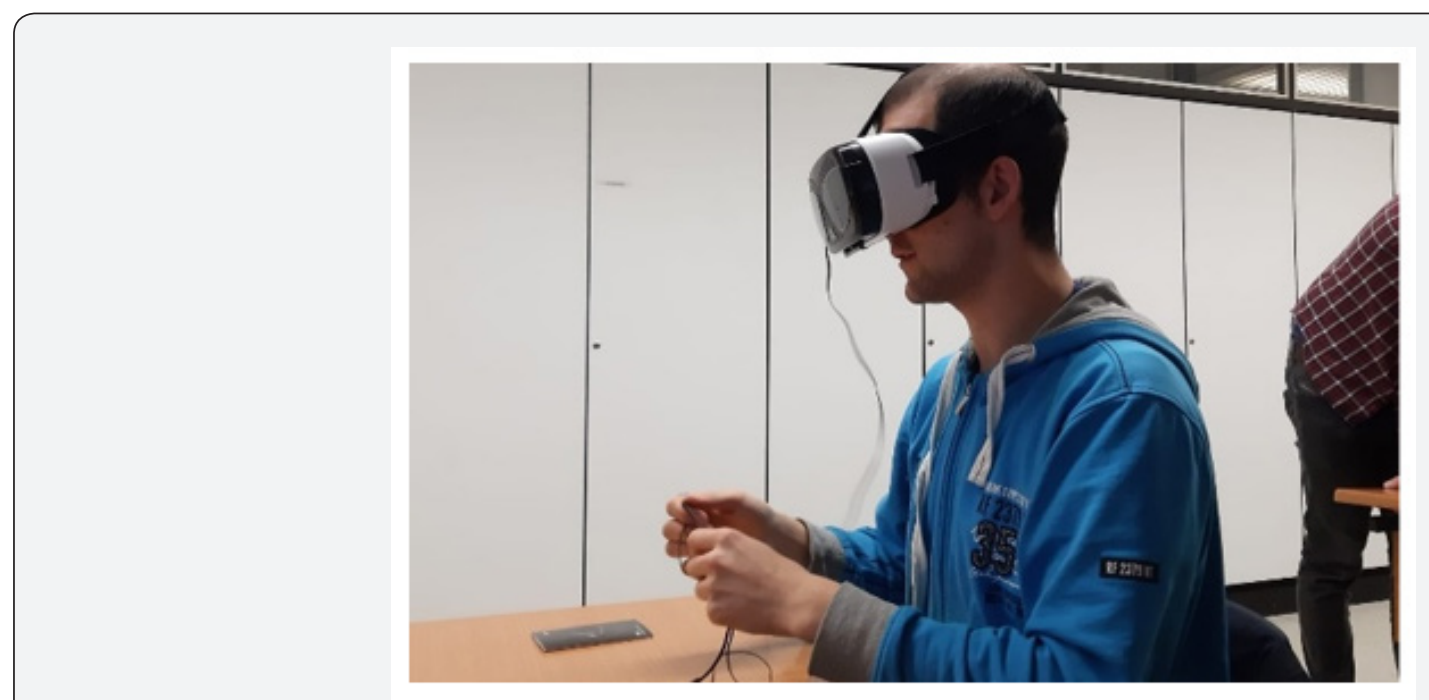

Figure 2: Virtual Reality in in Factory Planning class: Analysing the shop floor set-up regarding lean management and safety aspects.

Both approaches, the Virtual Reality and Mixed Reality realized on two different hardware platforms are currently used to demonstrate the impact of immersive teaching experience based on Virtual Reality (VR) and Mixed Reality interaction based on "Microsoft Hololens". Both platforms are used to implement and to assess the potentials of the novel education model. In order to reach these objectives, the project was realized in three phases: a) Stage 1 - Pilot Study: Generating an overview on the teaching content and test first proof of concepts in the lectures.

b) Phase 2 - Lecture Demonstrator: Integrating the new approach to the entire lecture "Factory Planning" and "Production Engineering"

c) Stage 3 - Students' Evaluation and Transfer: Providing detailed assessment on students by surveys and trials during 
and at the end of the term; Evaluate, how the approach can be transferred to selected courses.

\section{Implementation and Validation}

For educational purposes, the students in the "Factory Planning" course of the MSCP program virtually inspected a Tesla production site, which was provided in $360^{\circ} 3 \mathrm{D}$ video. Students analyzed the Tesla plant in Fremont, California with regard to Lean and safety.
The students were able to look around the factory floor and follow the production on a VR headset. The VR video displayed and provided the most important production steps, in which two lifethreatening situations were discussed by the students. With the VR tour, the lecturer wants to enable students to better understand what exactly happens in real production. VR technology can be used to simulate the dangerous situation in the production plant without endangering the students. Students can have a complete picture of a real working environment (Figure 3).

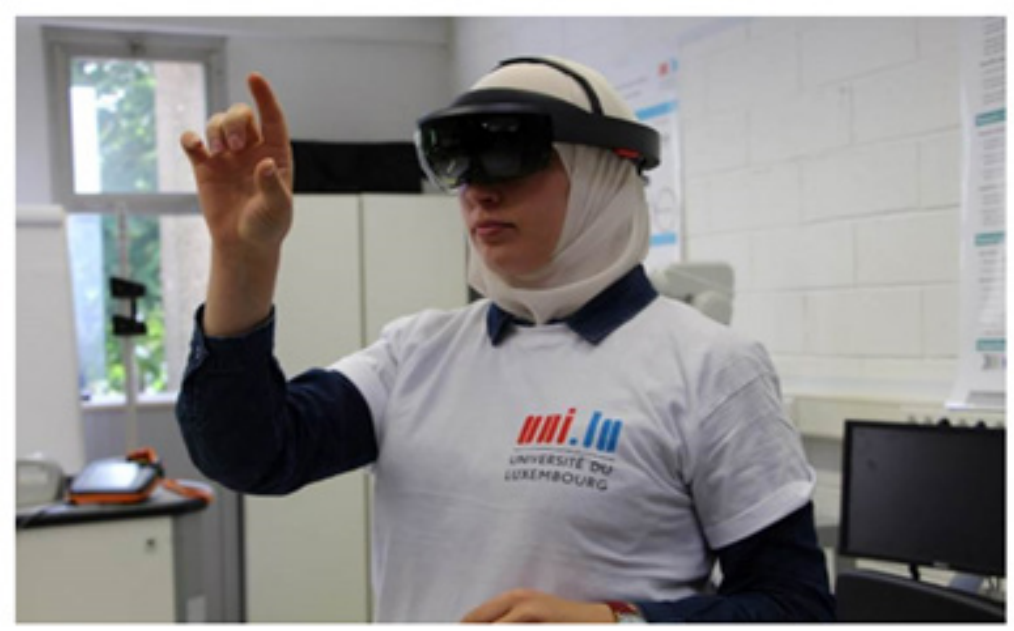

Figure 3: MR-based process design using the Hololens.

For the MR experience, we used the Microsoft Hololens and the Unity SDK as a scene graph, a common and straightforward approach to model kinematic chains of CNC machine tools, as shown in Figure 4.

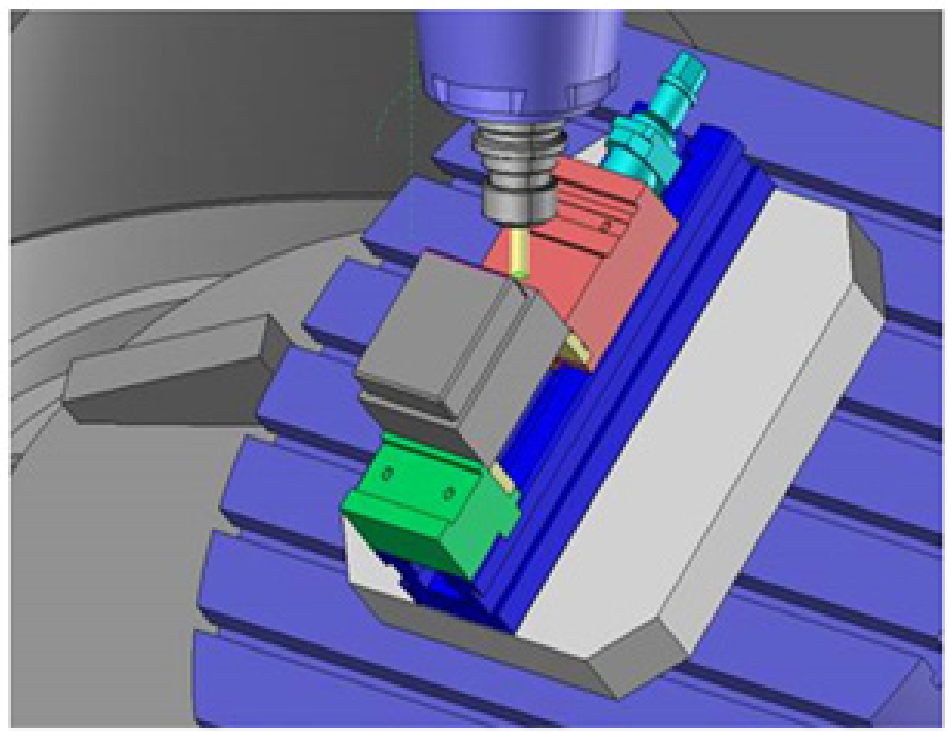

Figure 4: The process design using the Siemens NX CAD/CAM software. 
To demonstrate the Mixed Reality teaching concept, we used a DMU 50 evolution by the manufacturer DMG Mori to carry out the experiments in our facilities. The CNC machining simulation was linked to the MR headset, using a test geometry and the CNC machine in our shop floor. The test part consisted of simple geometric features: a cuboid machined on a rectangular clamping system, as shown in Figure 5. The used tool was a standard $10 \mathrm{~mm}$ diameter shaft mill with four cutting edges. While the NC program was running, the control computer provided real-time access to relevant process parameters, such as tool position and orientation.
Additional sensors for measuring power, torque, forces, and vibrations, can often be installed in the industrial machines [1]. In our setup, we did not consider dynamometers or other sensor technologies.

One of the main requirements for MR-based teaching was the capability to blend the user's view of the real environment with overlaid virtual images of the process. In our use case, holographic machine elements of the DMU 50 were overlaid in the Hololens headset, which allowed the students to simultaneously see the real environment, as well as overlaid 3D graphics (Figure 5).

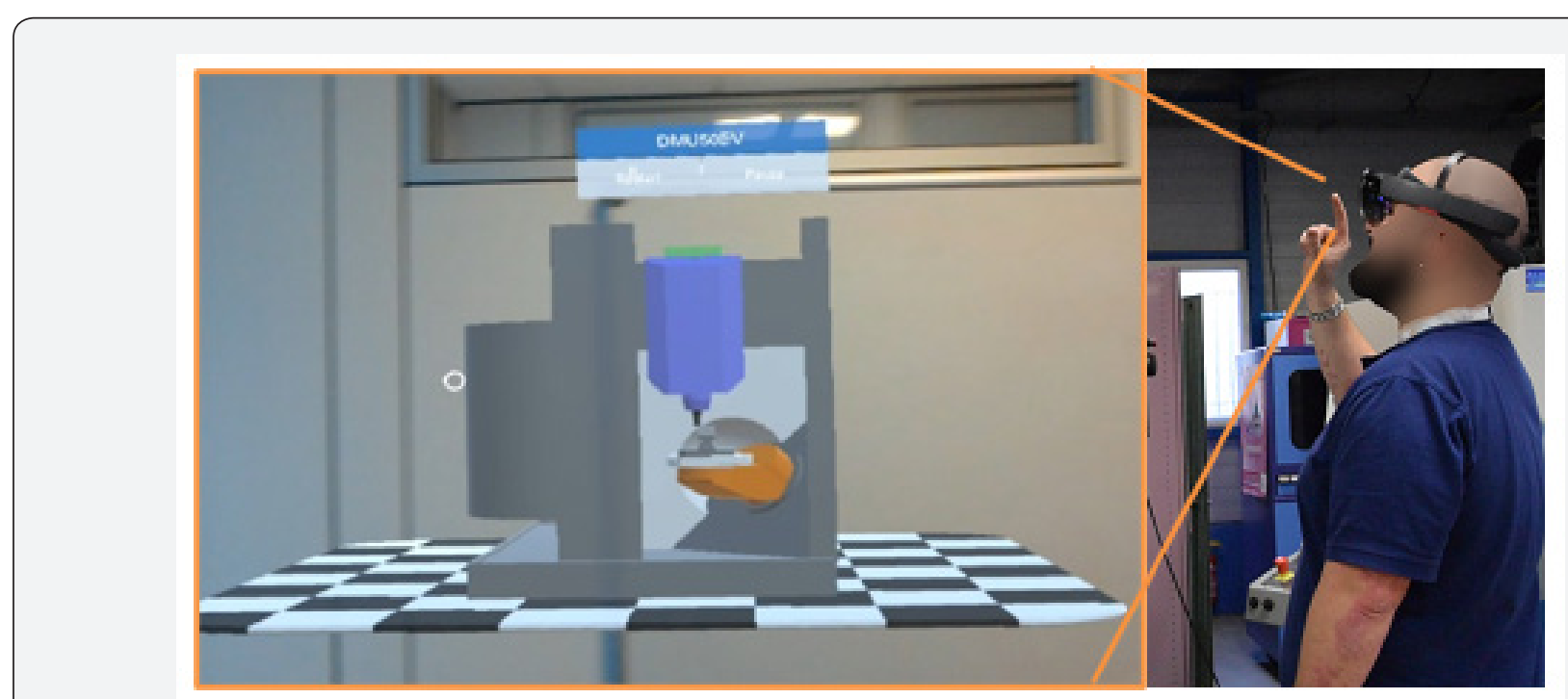

Figure 5: The operator views the machine operation through the Hololens, which is projecting stereoscopic images, augmenting the operator's view of the process with relevant information.

Providing real-time visual feedback to the students is specifically useful when she/he designs a new program or modifies existing ones and does not exactly know, how the result may impact the machine. Trials and tests with different tools provide a better understanding of the operation. The visualization of process data directly in the view field of the trainees provides intuitive access to the information [2-4].

\section{Conclusion}

Considering how teachers, trainers and lecturers in production engineering provide knowledge today, students and trainees often have difficulties to completely understand and follow the complex nature of the course. Especially when toady's production systems and processes become more complex and customized, the need of students learning new techniques increases amid increasing innovation speed and technology versatility.

Using books and flat two-dimensional digital documents, which do not involve spatial information, often consist of textual information, which is not the most appropriate way of providing technical information considering human cognitive and haptic abilities. Virtual and Mixed Reality (xR) offer the potential to integrate physical, digital and social learning experiences in hybrid learning environments and thereby to achieve learning gains, higher motivation or improved interaction and collaboration. Moreover, by means of $\mathrm{xR}$, technical- or engineering-based learning and experimental exploration in the lab can be brought closer together. Here we presented a data-driven xR enhancement of experiments in a Production Engineering and Factory Design course, where users could "beam" themselves into existing factories using VR or virtually create and modify production system using MR with head-mounted semi-transparent display (HMD).

The methods and concepts evaluated during the project can be adapted to other subjects of engineering sciences with reasonable amount of effort. Especially, civil engineers and product developers can benefit from the concept of the "HoloStudy" project (Figure 6). Prototypes will be instantly available during architectural and CAD design lectures. Subjects like anthropology and art history could stand to benefit from HoloStudy-based lessons, but really, any academic course featuring strong visual concepts may be suitable. 


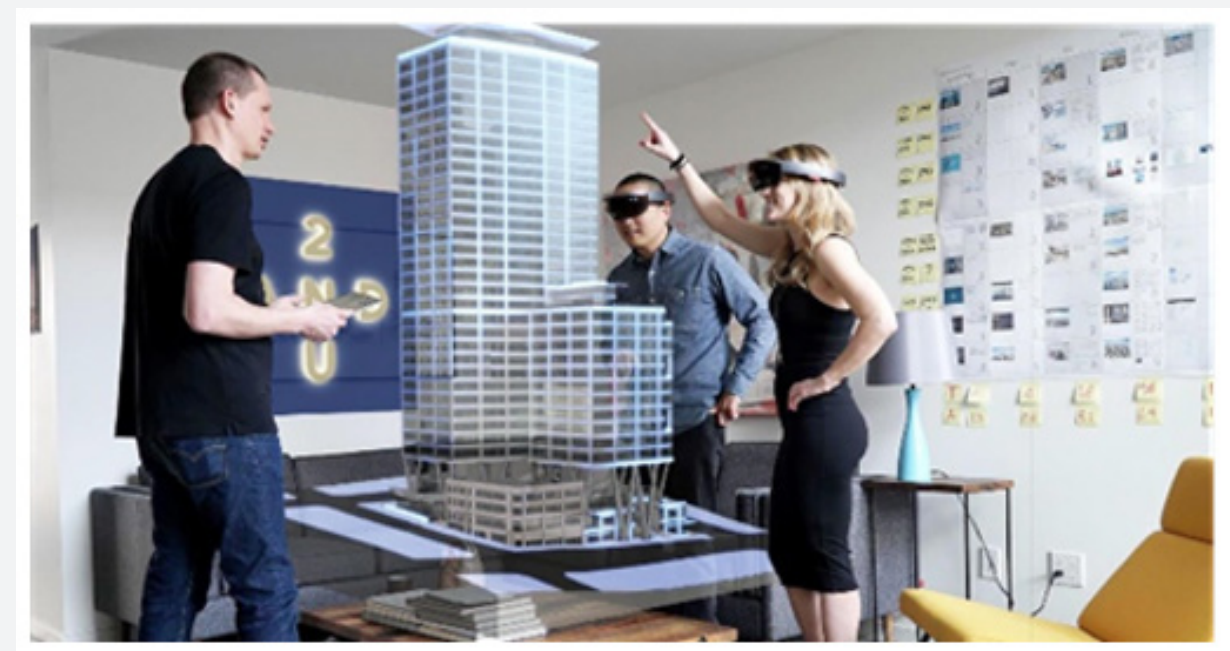

Figure 6: Latest HoloLens demo dazzles with holographic robot spiders and machine tools [3].

\section{References}

1. Minoufekr M, Glasmacher L, Adams O (2013) Macroscopic Simulation of Multi-axis Machining Processes. $10^{\text {th }}$ International Conference on Informatics in Control. Automation and Robotics (ICINCO), pp. 505516.

2. Baranowski A, Utzig S, Fischer PM, Gerndt A, Herder J (2018) 3D spacecraft configuration using immersive AR technology.
3. Janssen D, Stehling V, Richert AS, Isenhardt I (2019) Education 4.0: Teaching and learning in mixed reality.

4. Minoufekr M, Schug P, Joshi M (2014) Process Characterization and Evaluation of NC Machining Processes based on Macroscopic Engagement Simulation. $11^{\text {th }}$ International Conference on Informatics in Control, Automation and Robotics (ICINCO).

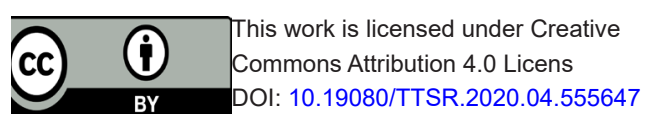

\section{Your next submission with Juniper Publishers will reach you the below assets}

- Quality Editorial service

- Swift Peer Review

- Reprints availability

- E-prints Service

- Manuscript Podcast for convenient understanding

- Global attainment for your research

- Manuscript accessibility in different formats ( Pdf, E-pub, Full Text, Audio)

- Unceasing customer service

Track the below URL for one-step submission https://juniperpublishers.com/online-submission.php 